Beate Hoecker (Hrsg.)

Handbuch Politische Partizipation von Frauen in Europa 
Beate Hoecker (Hrsg.)

\section{Handbuch Politische Partizipation von Frauen in Europa}

Leske + Budrich, Opladen 1998 
Die Übersetzung der Kapitel 1, 2, 4, 6, 7, 8, 9, 11, 13, 14 und 15 hat Christian Stahl vorgenommen.

Gedruckt auf säurefreiem und altersbeständigem Papier.

ISBN 978-3-8100-1782-6 ISBN 978-3-322-99810-1 (eBook)

DOI 10.1007/978-3-322-99810-1

C 1998 Leske + Budrich, Opladen

Das Werk einschließlich aller seiner Teile ist urheberrechtlich geschützt. Jede Verwertung außerhalb der engen Grenzen des Urheberrechtsgesetzes ist ohne Zustimmung des Verlages unzulässig und strafbar. Das gilt insbesondere für Vervielfältigungen, Übersetzungen, Mikroverfilmungen und die Einspeicherung und Verarbeitung in elektronischen Systemen.

Satz: Leske + Budrich 


\section{Inhalt}

Vorwort

I. Einleitung

\section{Politische Partizipation und Repräsentation von Frauen in den Staaten der Europäischen Union}

1. Belgien

Politische Partizipation in Belgien: Die gespaltene Frau

Alison E. Woodward

2. Dänemark

Frauen und politische Repräsentation in Dänemark

Ann-Dorte Christensen und Poul Knopp Damkjær

3. Deutschland

Zwischen Macht und Ohnmacht: Politische Partizipation von Frauen in Deutschland

Beate Hoecker

4. Finnland

Frauen in der finnischen Politik: Auf dem Weg zur Hälfte der Macht?

Solveig Bergman

5. Frankreich

Frauen in Frankreich: heiß geliebt und politisch kaltgestellt

Anette Kleszcz-Wagner 
6. Griechenland

Frauen als Akteurinnen in der politischen Kultur Griechenlands

Maria Pantelidou Maloutas

7. Großbritannien

Großbritanniens sexistische Demokratie: Frauen, Männer und die Politik im Parteienstaat

Joni Lovenduski

8. Irland

Die politische Repräsentation von Frauen in der Republik Irland

Yvonne Galligan

9. Italien

Die politische Repräsentation von Frauen in Italien: eine noch immer unvollendete Demokratie

Marila Guadagnini

10. Luxemburg

Luxemburg: Verspäteter politischer Einstieg der Frauen

Renée Wagener

11. Niederlande

Vom demokratischen Feigenblatt zur Parität. Politische Partizipation von Frauen in den Niederlanden

Monique Leijenaar

12. Österreich

Zwischen Konflikt und Konsens:

Frauen im politischen System Österreichs

Barbara Steininger

13. Portugal

Politische Partizipation und Repräsentation von Frauen in Portugal

Maria Regina Tavares da Silva

14. Schweden

Frauen, Männer und die politische Repräsentation in Schweden

Christina Bergqvist

15. Spanien

Politische Partizipation und Repräsentation von Frauen in Spanien 


\section{Außerhalb der EU:}

16. Der Fall Norwegen

An der Macht, aber nicht am Ziel: Politische Partizipation von Frauen in Norwegen

Frauke Rubart

\section{Politische Partizipation und Repräsentation von Frauen im europäischen Vergleich}

Beate Hoecker 


\section{Vorwort}

Die Idee zu diesem Handbuch beruht auf einem offenkundigen Mangel. Entgegen der Bedeutung des europäischen Integrationsprozesses für die Gleichberechtigung von Frauen hat deren politische Partizipation aus international vergleichender Perspektive bisher nur geringe wissenschaftliche Beachtung gefunden. Folglich wissen wir kaum etwas über den Stand der politischen Einflußnahme von Frauen in anderen westeuropäischen Staaten. Zwar gibt es einige Einzelfallstudien, doch ein Handbuch, das in systematischer Weise die institutionelle politische Partizipation und Repräsentation von Frauen in den Staaten der Europäischen Union dokumentiert und die Chancen sowie die Barrieren im jeweiligen politischen System analysiert, stellt in der deutschen wie internationalen Forschung noch immer ein Desiderat dar. Diese Forschungslücke soll mit dem vorliegenden Buch zumindest ansatzweise geschlossen werden.

Von der Idee bis zum Erscheinen des Handbuches sind knapp zwei Jahre vergangen, was für ein solch umfangreiches internationales Projekt eine relativ kurze Zeit ist. Zwar erwies sich die Suche nach Autorinnen für jedes Land teilweise schwieriger als gedacht, doch u.a. mit Hilfe des europäischen Expertinnen-Netzwerks „Women in Decision-Making“ konnte dieser Prozeß letztlich erfolgreich abgeschlossen werden. Die Autorinnen sowie der eine Autor sind überwiegend in der universitären Lehre und Forschung tätig und befassen sich in der Regel seit vielen Jahren mit dem Thema „Frauen und Politik“. Bis auf zwei Ausnahmen gehören sie der jeweiligen Nation an, über die sie berichten; dies war mir als Herausgeberin ein wichtiges Anliegen, da es authentische Kenntnisse nicht nur des betreffenden politischen Systems, sondern auch der gesellschaftlichen wie politischen Rolle von Frauen gewährleistet. Die Beiträge für Frankreich und Norwegen haben zwei deutsche Wissenschaftlerinnen verfaßt, die anerkannte Expertinnen für „ihre“ Länder sind.

Trotz vielfältiger anderer Belastungen haben sich die Autorinnen überwiegend an die konzeptionellen und zeitlichen Vorgaben gehalten. Bereitwillig nahmen sie auch die Mühe auf sich, die gewünschten empirischen 
Daten zusammenzutragen. Acht Autorinnen scheuten zudem nicht davor zurück, ihren Beitrag in englisch, also in einer für sie fremden Sprache zu verfassen. Ihnen allen gilt mein besonderer Dank.

Die kompetente Übersetzung der englischen Texte ins Deutsche hat Christian Stahl vorgenommen, dem ich dafür gleichfalls danke. Und schließlich ist es mir eine angenehme Pflicht, dem Verlag und hier insbesondere Barbara Budrich zu danken, die als Lektorin das Projekt von Anfang an begleitet und hilfreich unterstützt hat.

Riede, im August 1997

Beate Hoecker 